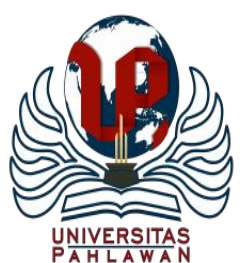

Jurnal Basicedu Volume 5 Nomor 1 Tahun 2021 Halaman 102-109

JURNAL BASICEDU

Research \& Learning in Elementary Education

https://jbasic.org/index.php/basicedu

\title{
Pengaruh Model Pembelajaran PAKEM terhadap Hasil Belajar Siswa di Sekolah Dasar
}

\author{
Raka Hermawan Kaban ${ }^{1}$, Dewi Anzelina ${ }^{2}$, Reflina Sinaga ${ }^{3}$, Patri Janson Silaban ${ }^{4}$ \\ Pendidikan Guru Sekolah Dasar Universitas Katolik Santo Thomas Medan, Indonesia ${ }^{1,2,3,4}$

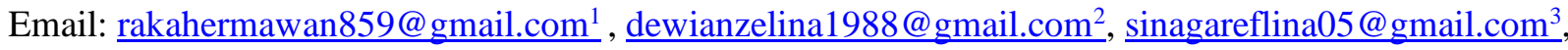 \\ patri_silaban280388@gmail.com ${ }^{4}$
}

\begin{abstract}
Abstrak
Penelitian ini bertujuan untuk mengetahui pengaruh model pembelajaran PAKEM terhadap hasil belajar siswa kelas V SD Negeri 047176 Sirumbia tahun pelajaran 2019/2020. Populasi penelitian ini adalah seluruh siswa SD Negeri 047176 Sirumbia berjumlah 45 siswa. Sampel yang digunakan dalam penelitian ini adalah sampel purposive sampling dalam hal ini peneliti memilih kelas $\mathrm{V}$ yang berjumlah 21 orang untuk dijadikan sebagai sampel dalam penelitian ini. Pada penelitian ini peneliti menggunakan metode kuantitatif sejenis survei metode yang digunakan dalam penelitian ini adalah metode kuantitatif jenis untuk menguji hipotesis dengan menggunakan teknik hipotesis, teknik hipotesis yang digunakan adalah hipotesis uji $t$. Hasil penelitian ini menunjukkan bahwa model pembelajaran PAKEM memiliki rata-rata 24,19 dengan kategori cukup dan hasil belajar memiliki 18,90 dengan kategori cukup hal ini didukung dengan hasil pengujian hipotesis uji t dimana nilai $t_{\text {hitung }}>t_{\text {tabel }}$ yaitu sebesar 4,196 $<1,720$, maka Ha diterima yaitu ada pengaruh yang signifikan antara model pembelajaran PAKEM terhadap hasil belajar kelas V SD Negeri 047176 Sirumbia tahun pelajaran 2019/2020.
\end{abstract}

Kata kunci: pengaruh, model pembelajaran PAKEM, hasil belajar

\section{Abstract}

This study aims to determine the effect of standardized learning models on the learning outcomes of grade $V$ SD Negeri 047176 Sirumbia for the 2019/2020 academic year. The population of this study were all students of SD Negeri 047176 Sirumbia, totaling 45 students. The sample used in this study is a sample purposive sampling in this case the researcher chooses class $V$, amounting to 21 people to serve as samples in this study. In this study, researchers used a quantitative method, a type of survey, the method used in this study was a quantitative method to test the hypothesis using the hypothesis technique, the hypothesis technique used was the t test hypothesis. The results of this study indicate that the standardized learning model has an average of 24.19 with a sufficient category and the learning outcomes have 18.90 with a sufficient category. that is, there is a significant influence between the standard learning model on the learning outcomes of class V SD Negeri 047176 Sirumbia for the 2019/2020 academic year.

Keywords: influence, PAKEM learning model, learning outcomes

Copyright (c) 2021 Raka Hermawan Kaban, Dewi Anzelina, Reflina Sinaga, Patri Janson Silaban

$\in$ Corresponding author:

Address : Universitas Katolik Santo Thomas

Email : rakahermawan859@gmail.com

ISSN 2580-3735 (Media Cetak)

Phone :

DOI $\quad$ : https://doi.org/10.31004/basicedu.v5i1.574 
103 Pengaruh Model Pembelajaran PAKEM terhadap Hasil Belajar Siswa di Sekolah Dasar- Raka Hermawan Kaban, Dewi Anzelina, Reflina Sinaga, Patri Janson Silaban

DOI: https://doi.org/10.31004/basicedu.v5i1.574

\section{PENDAHULUAN}

Pendidikan merupakan salah satu upaya untuk membangun dan meningkatkan mutu sumber daya manusia menuju era globalisasi yang penuh dengan tantangan sehingga didasari bahwa pendidikan merupakan sesuatu yang sangat fundamental bagi setiap individu. Oleh karena itu, kegiatan pendidikan tidak dapat diabaikan begitu saja, terutama dalam memasuki era persaingan yang semakin ketat, tajam, berat pada abad milenium ini. Pendidikan dilaksanakan secara terencana dan sistematis agar tujuan pendidikan dapat tercapai sesuai dengan harapan melalui kegiatan pembelajaran yang efektif dan efesien. Kegiatan pembelajaran terdiri atas perencanaan, pelaksanaan dan penilaian. Perencanaan mencakup pembuatan silabus dan Rencana Pelaksanaan Pembelajaran (RPP). Melalui perencanaan diharapkan kegiatan pembelajaran menjadi terarah sesuai dengan tujuan yang ditentukan. Pelaksanaan pembelajaran meliputi kegiatan penyampaian materi dengan menggunakan strategi atau metode serta media tertentu supaya pembelajaran berjalan efektif. Penilaian dalam kegiatan pembelajaran dilakukan untuk memantau seberapa efektif metode pembelajaran yang digunakan. Pembinaan juga sangat penting bagi siswa dimana pembinaan siswa adalah pemberian layanan kepada siswa di suatu lembaga pendidikan, baik di dalam maupun di luar jam belajarnya di kelas. Pembinaan kepada siswa dilakukan dengan menciptakan kondisi atau membuat siswa sadar akan tugas-tugas belajarnya.

Pendidikan memfokuskan perubahan tingkah laku manusia yang konotasinya pada pendidikan etika. Disamping itu pendidikan menekankan aspek produktifitas dan kreativitas manusia sehingga mereka bisa berperan serta berprofesi dalam kehidupan bermasyarakat. Semakin tinggi pendidikan yang akan dicapai seseorang maka akan semakin baik kehidupannya. Dalam dunia pendidikan harus ada proses belajar mengajar dilakukan supaya adanya interaksi guru dengan siswa.

(Simbolon, 2018) pendidikan adalah proses perubahan tingkah dan perilaku seseorang atau kelompok orang dalam usaha mendewasakan manusia melalui upaya pengajaran dan pelatihan. Dalam penelitian Silaban dan Hasibuan (2019) untuk menyikapi permasalahan yang timbul dalam proses pembelajaran. Pendidikan memegang kedudukan sentral dalam proses pembangunan dan kemajuan untuk menghadapi tantangan masa depan. Guru adalah orang yang memberikan ilmu pengetahuan kepada anak-anak didik. Guru dalam pandangan masyarakat adalah orang yang melaksanakan pendidikan di tempat-tempat tertentu, tidak mesti di lembaga pendidikan formal, tetapi bisa juga di lingkungan masyarakat dan di rumah. Guru memang menempati kedudukan yang terhormat di masyarakat, kewibawaanlah yang menyebabkan guru dihormati, sehingga masyarakat tidak meragukan figur guru. Masyarakat yakin bahwa gurulah yang dapat mendidik anak-anak mereka agar menjadi orang yang berkepribadian mulia. Dengan demikian dapat disimpulkan bahwa guru adalah semua orang yang bertanggung jawab untuk membimbing dan membina anak didik, baik secara individual maupun klasikal, di sekolah maupun di luar sekolah. 
104 Pengaruh Model Pembelajaran PAKEM terhadap Hasil Belajar Siswa di Sekolah Dasar- Raka Hermawan Kaban, Dewi Anzelina, Reflina Sinaga, Patri Janson Silaban

DOI: https://doi.org/10.31004/basicedu.v5i1.574

Proses belajar mengajar merupakan proses kegiatan interaksi antara dua pihak yakni siswa sebagai pihak yang belajar dan guru sebagai pihak yang mengajar dengan siswa sebagai siswa subjek pokoknya. Peranan dan tugas yang diemban guru sangat berat. Tugas guru tidak hanya mengajar, tetapi juga harus dapat mendidik, membimbing, membina, dan memimpin kelas yang memberikan pengarahan dan penuntun bagi siswa dalam belajar. Guru juga harus dapat melihat segala sesuatu yang terjadi di dalam kelas untuk membantu siswa melalui tahap perkembangannya .melalui peranannya sebagai pengajar, guru juga menjadi pelaku utama dan penentu berhasil atau tidaknya proses pembelajaran di sekolah. Gurulah yang merancang dan memilih materi, sumber belajar dan media pembelajaran.

Guru merupakan figur utama juga menjadi model atau contoh dan teladan bagi peserta didiknya. Oleh karena itu seorang guru harus memiliki pengetahuan, pengalaman, keterampilan dan kompetensi mengenai karakter serta memiliki karakter mulia dalam dirinya sendiri yang menjadi bagian dari hidupnya, karena apa yang dilakukannya dengan baik menjadi baik pula pengaruhnya terhadap peserta didik. Pendidikan sulit untuk menghasilkan sesuatu yang baik tanpa dimulai oleh guru-gurunya yang baik. Tugas guru tidaklah hanya berhenti sebagi pengajar yang melakukan transfer ilmu, tetapi sebagai motivator yang mampu membangkitkan motif atau keinginan siswa untuk mendapat hasil belajar yang jauh lebih baik. Banyak hal-hal yang mempengaruhi hasil belajar siswa baik faktor dari dalam yang mendorong siswa untuk melakukan sesuatu kegiatan walaupun tidak mendapat rangsangan dari orang lain dengan sadar dan dorongan itu berasal dari dalam diri siswa tersebut. Dan faktor dari luar adalah pengaruh dari/ lingkungan siswa berada yang mempengaruhi siswa untuk melakukan kegiatan.

Berdasarkan observasi awal yang dilakukan oleh peneliti ada beberapa hal faktor dari luar yang mempengaruhi hasil belajar siswa. Faktor-faktor tersebut antara lain sikap guru yang tidak menentu, pengelolaan kelas, penggunaan media pembelajaran, pihak orang tua siswa. Sikap guru yang tidak menentu selama proses pembelajaran mempengaruhi hasil belajar siswa. Kadang masih ada sikap guru yang otoriter, sikap guru yang tertutup pada siswa begitu juga siswa tertutup pada guru. Terkadang masih ada juga guru yang kurang memperhatikan siswanya, sehingga siswa kurang perduli selama proses pembelajaran. Jika guru belum mengobtimalkan kepemimpinan yang digunakan dalam proses pembelajaran maka siswa pun tidak mendapatkan hasil belajar yang baik serta suasana di dalam kelas tidak hidup dan berkembang. Untuk mengatasi itu perlu dikembangkan sikap demokratis dan terbuka serta perlu ada keaktifan dari pihak siswa dan guru harus bersikap ramah dan perhatian begitu juga sebaliknya siswa juga harus bersifat sopan, saling menghormati.

Pengelola kelas juga mempengaruhi hasil belajar siswa jika guru berhasil dalam mengelola kelas maka akan tercipta suasana atau kondisi belajar mengajar yang kondusif dan terjadinya hubungan yang baik antara guru dan siswa ataupun antara siswa dengan siswa karena siswa sudah 
105 Pengaruh Model Pembelajaran PAKEM terhadap Hasil Belajar Siswa di Sekolah Dasar- Raka Hermawan Kaban, Dewi Anzelina, Reflina Sinaga, Patri Janson Silaban

DOI: https://doi.org/10.31004/basicedu.v5i1.574

terbimbing untuk menjadi yang terbaik dalam kelasnya. Model pembelajaran PAKEM dalam kelas sangat mempengaruhi tercapainya hasil belajar siswa. Salah satunya adalah pengaruh model pembelajaran PAKEM terhadap hasil belajar siswa dimana model pembelajaran PAKEM pada dasarnya merupakan suatu proses dimana guru dapat mempengaruhi siswa yang didalamnya berisi serangkaian tindakan atau perilaku tertentu terhadap masing-masing siswa yang dipengaruhinya. Dengan model pembelajaran yang tepat yang digunakan dalam sistem belajar di kelas akan mengoptimalkan dan memaksimalkan keberhasilan pembelajaran di kelas serta membangkitkan minat belajar siswa untuk mendapatkan hasil belajar yang baik.

\section{Kajian Teori}

Menurut “ (Aunurrahman, 2010) Belajar adalah suatu kata yang sudah akrab dengan semua lapisan masyarakat". Bagi para pelajar atau mahasiswa kata "belajar" merupakan kata yang tidak asing. Bahkan sudah merupakan bagian yang tidak terpisahkan dari semua kegiatan mereka dalam menuntut ilmu di lembaga pendidikan formal. Kegiatan belajar mereka lakukan setiap waktu sesuai dengan keinginan. Entah malam hari, siang hari, sore hari, atau pagi hari.

(Hamalik, 2013) mengatakan kegiatan pembelajaran yang dibangun oleh guru dan siswa adalah kegiatan yang berhasil. Sebagai kegiatan yang berhasil, maka segala sesuatu yang dilakukan oleh guru dan siswa hendaknya diarahkan utnuk mencapai hasil yang telah ditentukan. Dengan demikian dalam proses pembelajaran, hasil merupakan pengikat segala aktifitas guru dan siswa. Oleh sebab itu, merumuskan hasil merupakan langkah pertama yang harus dilakukan dalam merancang sebuah program pembelajaran.

Menurut (Sugiono, 2018) "Model pembelajaran adalah sebagai suatu desain yang menggambarkan proses rincian dan penciptaan situasi lingkungan yang memungkinkan siswa berinteraksi sehingga terjadi perubahan atau perkembangan pada diri siswa”. Model pembelajaran adalah suatu pola atau langkahlangkah pembelajaran tertentu yang diterapkan dan dilaksanakan agar tujuan atau kompetensi dari hasil belajar yang diharapkan akan cepat dicapai dengan lebih efektif dan efisien. Jika hal ini berhasil berarti model pembelajaran tersebut berhasil mengubah dan meningkatkan kualitas belajar siswa tersebut.

Menurut (Kurniawan, 2014) Rusman Menyatakan bahwa pengertian "PAKEM adalah pendekatan pembelajaran yang lebih banyak melibatkan aktivitas siswa dalam mengakses berbagai informasi dan pengetahuan untuk dibahas dan dikaji dalam proses pembelajaran dikelas, sehingga mereka mendapatkan berbagai pengalaman yang dapat meningkatkan pemahaman dan kompetensinya".

\section{METODE}

Pendekatan penelitian ini adalah penelitian kuantitatif. Menurut Noor (2012:38) penelitian kuantitatif merupakan metode untuk menguji teoriteori tertentu dengan cara meneliti hubungan antar variabel. Metode penelitian merupakan suatu 
106 Pengaruh Model Pembelajaran PAKEM terhadap Hasil Belajar Siswa di Sekolah Dasar- Raka Hermawan Kaban, Dewi Anzelina, Reflina Sinaga, Patri Janson Silaban

DOI: https://doi.org/10.31004/basicedu.v5i1.574

langkah atau cara yang ditempuh dalam mengumpulkan, mengorganisasikan serta menginterprestasikan data.

Menurut Sugiyono (2016:3) metode penelitian pada dasarnya merupakan cara ilmiah untuk mendapatkan data dengan tujuan dan kegunaan tertentu yang didasarkan pada ciri-ciri keilmuan yaitu, rasional, empiris, dan sistematis. Maka metode penelitian yang digunakan dalam penelitian ini adalah metode deskriptif. Metode deskriptif merupakan metode penelitian yang bermaksud menjelaskan kedudukan variabel yang diteliti serta pengaruh antara suatu variabel dengan variabel yang lain.

\section{HASIL DAN PEMBAHASAN}

Tabel 1. Frekuensi Kategori Model Pembelajaran PAKEM

\begin{tabular}{cccc}
\hline Skor & Frekuensi & Persentase & Kategori \\
\hline $\mathbf{2 8 , 2 5}-\mathbf{3 2 , 0}$ & 4 & $19,04 \%$ & Sangat \\
& & & Tinggi \\
$\mathbf{2 5 , 7 5}-\mathbf{2 8 , 2 5}$ & 3 & $14,28 \%$ & Tinggi \\
$\mathbf{2 3 , 2 5}-\mathbf{2 5 , 7 5}$ & 3 & $14,28 \%$ & Cukup \\
$\mathbf{2 0 , 7 5}-\mathbf{2 3 , 2 5}$ & 8 & $38,09 \%$ & Kurang \\
$\mathbf{1 7 , 0}-\mathbf{2 0 , 7 5}$ & 3 & $14,28 \%$ & Rendah \\
\hline
\end{tabular}

Berdasarkan tabel frekuensi kategori model pembelajaran PAKEM bahwa kategori sangat tinggi sebesar 19,04\%, kategori kurang sebesar 38,09\%, sedangkan kategori cukup sebesar, kategori rendah dan kategori tinggi sebesar $14,28 \%$. Jadi yang paling dominan adalah kategori kurang sebesar 38,09\%. Sehingga dapat disimpulkan bahwa model pembelajaran PAKEM di SD Negeri 047176 Sirumbia masih kurang, baik dalam segi pengajaran materi ataupun dalam penggunaan model pembelajaran PAKEM.

Tabel 2. Frekuensi Kategori Hasil Belajar Siswa

\begin{tabular}{rlccl}
\hline No & Skor & Frekuensi & Persentase & Kategori \\
\hline 1. & $\begin{array}{l}22,46- \\
26,0\end{array}$ & 4 & $19,04 \%$ & $\begin{array}{l}\text { Sangat } \\
\text { Tinggi }\end{array}$ \\
\hline 2. & $\begin{array}{l}20,15- \\
22,46\end{array}$ & 4 & $19,04 \%$ & Tinggi \\
& $\begin{array}{l}\text { 22, } \\
\text { 3. }\end{array} \begin{array}{l}17,85- \\
20,15\end{array}$ & 7 & $33,3 \%$ & Cukup \\
\hline 4. & $\begin{array}{l}15,55- \\
17,85\end{array}$ & - & - & Kurang \\
5. & $11,5-$ & 6 & $28,57 \%$ & Rendah \\
& 15,55 & & & \\
\hline
\end{tabular}

Berdasarkan tabel frekuensi kategori hasil belajar di atas bahwa hasil belajar siswa dalam kategori cukup sebesar 33,3\%. Sehingga dapat disimpulkan bahwa hasil belajar siswa di SD Negeri 047176 Sirumbia dalam kategori cukup. Artinya hasil belajar siswa banyak yang belum tuntas (di bawah nilai KKM).

\section{Uji Normalitas}

Uji normalitas bertujuan untuk menguji apakah dalam model regresi, variabel pengganggu atau residual memiliki distrbusi normal. Uji normalitas sebagai salah satu uji prasyarat yang harus dipenuhi agar analisis regresi dapat dilakukan, baik untuk keperluan prediksi maupun untuk keperluan pengujian hipotesis. Uji normalitas dengan grafik dapat menyesatkan kalau tidak hati-hati secara visual kelihatan normal, pada hal secara statistik bisa sebaliknya. Oleh sebab itu dianjurkan disamping uji grafik dan histogram dilengkapi dengan uji statistik. Oleh karena itu penulis melakukan uji statistik pada uji normalitas 
107 Pengaruh Model Pembelajaran PAKEM terhadap Hasil Belajar Siswa di Sekolah Dasar- Raka Hermawan Kaban, Dewi Anzelina, Reflina Sinaga, Patri Janson Silaban

DOI: https://doi.org/10.31004/basicedu.v5i1.574

ini. Penulis menggunakan uji normalitas statistik dengan Test Statistic Kolmogorov-Smirnov pada alpha sebesar 5\%. Jika nilai signifikan dari pengujian Kolmogorov-Smirnov lebih besar dari 0,05 berarti data normal, jika tidak maka data berdistribusi normal.

Tabel 3. Hasil Pengujian Normalitas One-Sample Kolmogorov-Smirnov Test

\begin{tabular}{llr}
\hline \multicolumn{2}{c}{ One-Sample Kolmogorov-Smirnov Test } \\
\hline & & $\begin{array}{r}\text { Unstandardiz } \\
\text { ed Residual }\end{array}$ \\
$\mathbf{N}$ & Mean & 21 \\
Normal &, 0000000 \\
Parameters ${ }^{\text {a,b }}$ & Std. & 3,74444544 \\
& Deviation & \\
Most Extreme & Absolute &, 144 \\
Differences & Positive &, 144 \\
& Negative &,- 114 \\
Test Statistic & &, 144 \\
Asymp. Sig. (2-tailed) & &, $200^{\text {c,d }}$ \\
\hline
\end{tabular}

Berdasarkan uji normalitas dengan Kolmogorov-Smirnov Test diperoleh nilai signifikan sebesar 0,2 lebih besar dari dari $\alpha=0,05$ maka dapat disimpulkan data tersebut berdistribusi normal.

\section{Uji Hipotesis}

Pengujian hipotesis pada pengujian ini dilakukan dengan menggunakan uji parsial $t$ dengan berbantuan program SPSS Versi 22.0. Uji $t$ digunakan untuk mengetahui adanya pengaruh variabel bebas terhadap variabel terikat yaitu variabel model pembelajaran PAKEM terhadap hasil belajar siswa. Pengujian hipotesis dengan menggunakan uji $t$ dilakukan dengan cara membandingkan $t_{\text {hitung }}$ dengan $t_{\text {tabel }}$. Kriteria pengujian dengan menggunakan uji t adalah jika $t_{\text {hitung }}>t_{\text {tabel }}$ hipotesis alternatif diterima dan jika $t_{\text {hitung }}<t_{\text {tabel }}$ hipotesis alternatif ditolak. Hipotesis yang pertama dalam penelitian ini adalah:

Ho : Tidak ada pengaruh yang signifikan model pembelajaran PAKEM siswa terhadap hasil belajar siswa

Ha :Ada pengaruh yang signifikan anatara model pembelajaran PAKEM terhadap hasil belajar siswa

Berikut akan disajikan tabel dan hasil pengujian hipotesis dengan berbantuan program SPSS Versi 22.0 sebagai berikut:

Tabel 4. Uji Hipotesis

\begin{tabular}{|c|c|c|c|c|c|c|}
\hline \multicolumn{7}{|c|}{ Coefficients $^{a}$} \\
\hline \multirow{2}{*}{\multicolumn{2}{|c|}{ Model }} & & $\begin{array}{l}\text { dardiz } \\
d \\
\text { icients }\end{array}$ & $\begin{array}{c}\text { Standar } \\
\text { dized } \\
\text { Coeffic } \\
\text { ients }\end{array}$ & \multirow[t]{2}{*}{$\mathrm{t}$} & \multirow[t]{2}{*}{$\begin{array}{l}\mathrm{Si} \\
\text { g. }\end{array}$} \\
\hline & & B & $\begin{array}{l}\text { Std. } \\
\text { Error }\end{array}$ & Beta & & \\
\hline \multirow[t]{6}{*}{1} & (Con & 22 & 5,252 & & 4, &, 0 \\
\hline & stant &, 0 & & & 19 & 00 \\
\hline & ) & 39 & & & 6 & \\
\hline & VAR & - & ,214 &,- 137 & - &, 5 \\
\hline & IAB &, 1 & & &, 6 & 53 \\
\hline & EL_ & 30 & & & 04 & \\
\hline
\end{tabular}

a. Dependent Variable: VARIABEL_Y

Berdasarkan tabel di atas diketahui bahwa nilai $t_{\text {hitung }}$ sebesar 4,196 dan $t_{\text {tabel }}$ sebesar 1,720 , sehingga $t_{\text {hitung }}>t_{\text {tabel }}$ maka Ha diterima yaitu ada pengaruh yang signifikan antara model pembelajaran PAKEM terhadap hasil belajar siswa.

\section{SIMPULAN}


108 Pengaruh Model Pembelajaran PAKEM terhadap Hasil Belajar Siswa di Sekolah Dasar- Raka Hermawan Kaban, Dewi Anzelina, Reflina Sinaga, Patri Janson Silaban

DOI: https://doi.org/10.31004/basicedu.v5i1.574

Berdasarkan analisis data dan pengujian hipotesis serta pembahasan, maka dapat ditarik kesimpulan sebagai berikut:

1. Model pembelajaran PAKEM memiliki nilai rata-rata sebesar 24,19 dapat disimpulkan bahwa model pembelajaran PAKEM di SD Negeri 047176 Sirumbia masih cukup. Bentuknya baik dalam segi pengajaran materi ataupun dalam penggunaan model pembelajaran PAKEM sehingga model pembelajaran PAKEM memperoleh kategori cukup.

2. Hasil belajar Matematika siswa kelas IV SD Negeri 047176 Sirumbia sebanyak 21 siswa dengan nilai rata-rata 18,90 dengan kategori cukup. Hasil belajar siswa di SD Negeri 047176 Sirumbia sebanyak 21 siswa dalam kategori cukup. Artinya hasil belajar siswa banyak yang belum tuntas.

3. Terdapat pengaruh yang signifikan antara model pembelajaran PAKEM memiliki pengaruh terhadap hasil belajar siswa hal tersebut terbukti dari nilai $t_{\text {hitung }}>t_{\text {tabel }}$ yaitu 4,196>1,720. Maka dengan demikian Ha diterima yaitu ada pengaruh yang signifikan antar model pembelajaran PAKEM dengan hasil belajar. Dari hasil penelitian ini dapat disimpulkan bahwa model pembelajaran PAKEM memiliki pengaruh terhadap hasil belajar siswa.

\section{DAFTAR PUSTAKA}

Susanto, A. (2016). Teori Belajar Pembelajaran. Jakarta: Prenadamedia Group.
Widya, A. Pengaruh Kecerdasan Emosional Siswa Terhadap Hasil Belajar Tematik Integratif Di Kelas. 2017. Universitas Islam Negeri Maulana Malik Ibrahim, Malang.

Zain, S. B. (2016). Strategi Belajar Mengajar. Jakarta: Rineka Cipta.

Arikunto, S. (2012). Dasar-dasar Evaluasi Pendidikan. Jakarta: PT Bumi Aksara.

Aunurrahman. (2010). Belajar dan Pembelajaran. Bandung: Alfabet.

Hamalik, O. (2013). Proses Belajar Mengajar. Jakarta: PT Bumi Aksara.

Holland, R. (2015). Kamus Matematika. Jakarta: Erlangga.

Kurniawan, D. (2014). Pembelajaran Terpadu Tematik. Bandung: Alfabet.

MANULLANG, M. (2019). PENERAPAN MODEL PEMBELAJARAN MIND MAPPING. Pendidikan Guru Sekolah Dasar Juril AQUINAS, 113.

MANULLANG, M. (2019). PENERAPAN MODEL PEMBELAJARAN MIND MAPPING. Pendidikan Guru Sekolah Dasar Juril AQUINAS , 113.

Margono. (2018). Metode Penelitian Pendidikan. Jakarta: Rineka Cipta.

Mudjiono, D. d. (2013). Belajar dan Pembelajaran. Jakarta: Rineka Cipta.

Purwanto. (2010). Evaluasi Hasil Belajar. Surakarta: Pustaka Pelajar..

Slameto. (2010). Belajar dan Faktor-faktor Yang Mempengaruhi. Jakarta: Rineka Cipta.

Sri Anitah. (2017). Strategi Pembelajaran di SD. Jakarta: Universitas Terbuka.

Sudjana. (2016). Metode Statistika. Bandung: Tarsito.

Sugiono. (2018). Metode Penelitian. Bandung: Alfabet.

Suratman. (2018). Upaya Meningkatkan Hasil Belajar Matematika Pada Materi Sifat-sifat Operasi Hitung Melalui Metode Pembelajaran Tegak Lurus. Jurnal Education dan Economis, Vol 1 No 4. 
109 Pengaruh Model Pembelajaran PAKEM terhadap Hasil Belajar Siswa di Sekolah Dasar- Raka Hermawan Kaban, Dewi Anzelina, Reflina Sinaga, Patri Janson Silaban

DOI: https://doi.org/10.31004/basicedu.v5i1.574

Surya. (2005). Bimbingan dan Konseling. Jakarta: Universitas Terbuka.

Susanto, A. (2016). Teori Belajar Pembelajaran. Jakarta: Prenadamedia Group.

Widya, A. Pengaruh Kecerdasan Emosional Siswa Terhadap Hasil Belajar Tematik Integratif Di Kelas. 2017. Universitas Islam Negeri Maulana Malik Ibrahim, Malang. 